\title{
A NOTE ON THE VENOUS PULSE IN PAROXYSMAL TACHYCARDIA
}

\author{
FRANCIS W. PEABODY, M.D. \\ BALTIMORE
}

While paroxysmal tachycardia is a clinically well-recognized symptom-complex, its exact pathology is not as yet by any means understood. The introduction of graphic methods in the study of cardiac phenomenat has already resulted in some light being thrown on this condition, and it is only through such means that its ultimate explanation may be looked for. Since, however, the number of cases in the literature of which good venous tracings have been taken is decidedly limited, it has seemed worth while to report two instances in which records of the jugular pulse were obtained.

In general it may be said that from the point of view of the venous pulse all cases of paroxysmal tachycardia apparently fall into one of two groups (Hirschfelder, ${ }^{1}$ Schmoll ${ }^{2}$ ). The first includes those cases in which the venous pulse is of the normal or "auricular" type. In the second class the venous pulse assumes the "ventricular" or "positive" type, and there is no evidence of any contraction of the auricles. Cases of the first class have been reported by Schmoll ${ }^{2}$ and by Cowan, McDonald and Binning. ${ }^{3}$ Cases in which the venous pulse is "ventricular" have been described by Schmoll, ${ }^{2}$ Rihl, ${ }^{4}$ Hay, ${ }^{5}$ Hirschfelder ${ }^{6}$ and Mackenzie. ${ }^{7}$ In a discussion of this subject it is of the utmost importance, as Hirschfelder ${ }^{1}$ has pointed out, to distinguish between cases of idiopathic paroxysmal tachycardia, with sudden onset and cessation, and cases of simple rapid heart action beginning and ending more or less gradually.

1. Hirschfelder: Contributions to the study of auricular fibrillation, paroxysmal tachycardia, and the so-called auriculo-(atrio)-ventricular extrasystoles. Johns Hopkins Hosp. Bull., 1908, xix, 322.

2. Schmoll: Paroxysmal tachycardia. Am. Jour. Med. Sc., 1907, exxxiv, 662.

3. Cowan, McDonald and Binning: The venous pulse in paroxysmal tachycardia. Quart. Jour. Med., 1909, ii, 146.

4. Rihl: Atrioventrikuläre Tachycardie beim Menschen. Deutsch. merl. Wehnsehr., 1907, xxxiii, 632.

5. Hay: Paroxysmal tachycardia. Edinburgh Med. Jour., 1907, xxi, 40.

6. Hirschfelder: Observations on paroxysmal tachycardia. Johns Hopkins Hosp. Bull., 1906, xvii, 337.

7. Mackenzie: Diseases of the heart. London, 1908. 
The following cases were observed in the wards of the Johns Hopkins Hospital, and I am indebted to Dr. Barker and Dr. Thayer for permission to report them:

CAse 1.-M. M., female, general number 67,343, medical number 23,725, mar ried, aged 33, admitted Feb. 16, 1909, discharged March 9, 1909, complains of "fluttering round heart, and pain in chest and back."

History.-Family history good. She has been married seventeen years and has had seven children. Had diphtheria when a child, but recovered without complications. Seven years ago she had typhoid fever; "chills and fever" three times in the last three years. Two months ago she had pneumonia. Otherwise she has always been well. Average weight 115 pounds.

Present Illness.-For some months she has suffered from "aching in bones," "extreme weariness," and shortness of breath on slight exertion. Occasionally she has had some slight "fluttering around heart." Two weeks ago all her symptoms
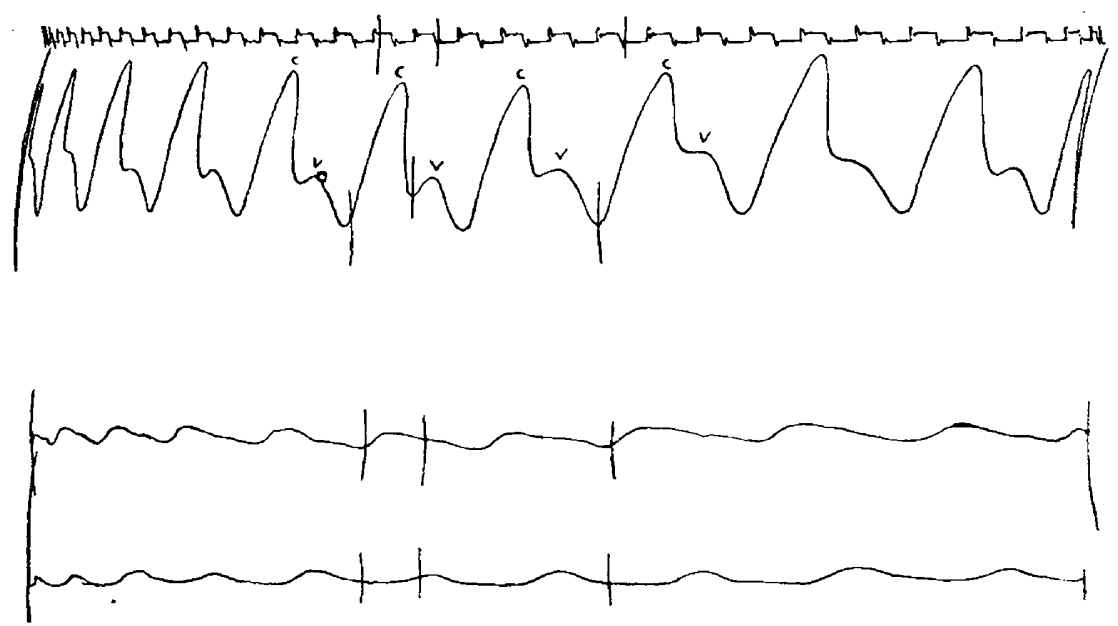

Fig. 1.-Paroxysmal tachycardia, Case 1; pulse rate, 215. In all tracings, timer marks tenths of seconds; lowest tracing is from the brachial artery, the second from the carotid artery, and the third from the jugular vein.

became worse, and eight days ago she had an attack of "fluttering" which lasted for nine hours. Similar attacks lasting for longer or shorter periods have recurred every day since. She has been in bed for a week, and during this time has had drenching sweats every night. She has been nursing her baby and her breasts are still lactating. Hemoglobin, 75 per cent.; red cells, 4,000,000; white cells, 10,600 .

Physical Examination.-This shows a poorly nourished, very pale woman. There are no physical signs of importance except in the heart. The apex impulse is felt in the fourth space, $7 \mathrm{~cm}$. to the left of the mid-sternal line. The relative cardiac dulness extends $10 \mathrm{~cm}$. to the left in the fourth space, above to the upper border of the third rib, and to the right $3 \mathrm{~cm}$. from the mid-sternum. The rate is 200 to the minute. There is no arrhythmia. No murmurs can be distinguished except for a "short, high-pitched. apparently systolic murmur," which is localized in the tricuspid area. The lungs are clear. The liver flatness extends from the 
sixth rib to $3 \mathrm{~cm}$. below the costal margin in the right manmary line, the edge doubtfully palpable. The radial pulse is extremely weak, scarcely more than a flutter. To pitting over ankles.

Course of Disease.-February 17: This morning the pulse rate is 90 , and the loud systolic blow, maximum over the tricuspid area, has disappeared.

February 18: At 5:30 p. m. the patient complained of "fluttering of the heart," and the heart's rate, taken at the apex, was found to have risen from 90 to 200 . At about $8 \mathrm{p}, \mathrm{m}$. tracings of the venous pulse were taken (Fig. 1). Pressure was then made over the vagus nerve in the neck, and the rate dropped suddenly from 200 to 116 (Fig. 2). The patient was much relieved and said she felt as if she would go to sleep.

On the following morning the pulse rate was 100 .

On the day after admission there was a trace of albumin in the urine, but the examinations have otherwise been negative. The blood pressure has ranged from 76 to $102 \mathrm{~mm}$.

After the attack of tachycardia, which was stopped by pressure on the vagus, she remained free from attacks until her discharge from the hospital on March 9. During this time the pulse rate ranged from $\$ 0$ to 126 , being generally about 100 .

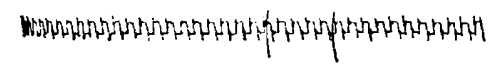
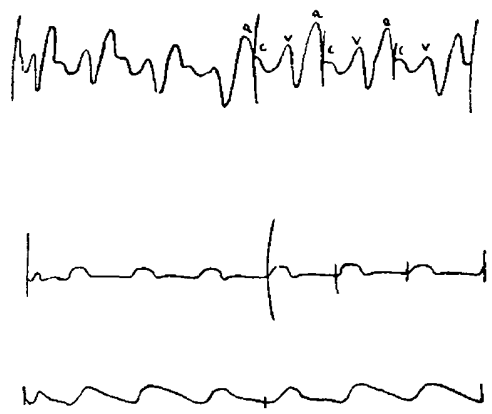

Fig. 2.- Formal rhỵthm after pressure on ragus nerve in neck, Case 1; pulse rate, 120 .

Tracings from the jugular vein, the carotid and brachial arteries were taken from this case during the attack and immediately after the attack was stopped by pressure on the vagus. The renous pulse during the attack shows only two wares-one beginning about 0.02-0.05 seconds before the rise on the carotid pulse-obviously the $c$ wave- and a second, less marked wave following. The latter is probably the $v$ wave. The onset of this second wave occurs on an arerage 0.11 seconds before the next $c$ wave, and it is, of course, possible that this might represent an $a$ wave of auricular contraction. If it were an $a$, however, one would expect a larger ware, as it falls during ventricular systole. Moreover, it would be unusual to have so large a depression between $a$ and $c$ wares. The beginning of the $v$ ware occurs $0.1: 9$ seconds after the $c$ ware at 
the normal rate, and at the rapid rate 0.160 seconds alter the $c$. The relations of the crest of this sccond wave at the rapid rate, and of the $r$ wave at the normal rate, to the djcrotic notch on the carotid artery are the same-both falling 0.03 seconds after the notch. The most probable explanation of the eurve, therefore, is that it is a "ventricular" renous pulse. The tracing taken after the attack was stopped shows the resumption of the normal, "auricular" venous pulse with a well-marked $a$ wave, a $c$ wave, and a $v$ wave. The conduction time-the a-c interval-is in this case from 0.16 to 0.19 seconds.

Case 2.-Male, single, aged 29, general number 67,086 , medical number 23,646 , admitted during an attack of paroxysmal tachycardia.

History-Family history good. Patient had scarlet fever at 14; acute articular rheumatism at 16 . This was not followed by any apparent complication until he began to have shortness of breath, and on examination a mitral stenosis was discovered five years ago. For some time he has had attacks of palpitation of the leart in which the rate jumps from about 86 up to 180 per minute. These attackis of tachycarlia occurred at first at intervals of about a month, lut they have been much more frequent of late. Sometimes he has several in a week. The duration has raried from thirty seconds to twenty-seven hours. In the Jonger attacks he sometimes las cough and foamy or bloody expectoration, especially if he lies on his lack. The attacks often begin without any obvious cause, hut may follow a quick or sudden movement. During them he feels rather weak, and is troubled by the forcible "thumping" of his heart, but except in the longer attacks he is never forced to go to bed. Many of the attacks he is able to stop by pressure on the vagus in the neek, by romiting, by tickling the back of the throat with his finger, or by deep inspiration. Putting the finger down the throat or inducing romiting are fairly reliable methods of aborting the attacks. More severe attacks cease only after pressure on the vagus lasting several minutes. Some of them, however, do not yieid to any method which has been employed. The longest attack-twenty-seven hours-stopped an hour and forty minutes after the intravenous injection of $1 \mathrm{mg}$. of strophanthin. It is, of course'. doubtful whether the drug was a factor in its cessation. One attack stopped about three minutes after a similar injection of strophanthin, but as another began in a few hours, during the period over which the drug should still be active, there is no reason to suppose that the strophanthin itself had any effect. A variety of other drugs produce no results. Juring the attacks the pulse rate is usually about $180-190$, and between attacks it is about 87 . It is worthy of note that an $x$-ray examination las shown an osteoarthritis of the cervical spine.

Physical Examination of the Heart.-While the heart's rate is 72 , the apex impulse is in the fifth space, $8.5 \mathrm{~cm}$. from the median line. The relative cardiac dulness extends from $3.8 \mathrm{~cm}$. to the right in the fourth space, to $9 \mathrm{~cm}$. to the left of the median line in the fifth space. The first sound is well heard $20 \mathrm{~cm}$. from the chest without the aid of a stethoseope. On auscultation it is sharp and snapping, and there is a characteristic presystolic murmur which begins with a bruit de rappel very soon after the second sound. The murmur is not audible in the axilla where the bruit do rappel is heard with great intensity. The accentuation of the pulmonic second is not great. The lungs are clear. The liver is not enlarged. Blood pressure, $80-90$.

Diagnosis.-The case is thus one of mitral stenosis associated with attacks of paroxysmal taelycarlia. On some examinations a very faint diastolie murmur o: aortic regurwitation has been heard, and at times a soft systolic murmur has been 
noted at the apex. The possibility of the cervical osteoarthritis being a factor in the cause of the paroxysmal tachycardia by acting on the vagus nerve cannot be excluded.

Tracings have been taken from the jugular vein, the carotid and brachial arteries during two of his attacks. Figure 3 shows the type of curve which was obtained on both occasions. The venous pulse is of the same form as that in Case 1. There are two waves, one beginning 0.018 to 0.025 seconds before the carotid rise, obviously the $c$ wave, and a second which follows it. This second wave begins on an average 0.15 seconds before the $c$ wave. Its onset is 0.156 seconds after the $c$ wave, while the $v$ wave at the normal rate begins 0.24 seconds after the $c$ wave. The crest of the second wave falls 0.060 seconds after the dicrotic notch on the carotid, approximately the same time relation as that of the $v$ at the normal rate, which falls 0.056 seconds after the di-

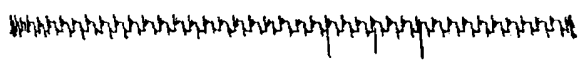
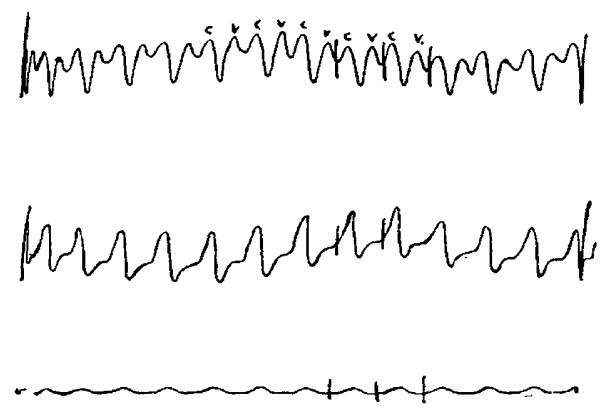

Fig. 3.-Paroxysmal tachyeardia, Case 2; "ventricular" venous pulse; pulse rate, 193 .

crotic notch. It is impossible to prove that this is not the wave of auricular contraction, but, as in the other case, it seems much more probable that it is a $v$ wave, and that we have here also a "ventricular" venous pulse. If one should assume that this is an $a$ wave, then the a-c time-the time of transmission of the impulse from auricle to ventricle - when the heart's rate is 193 , is 0.15 seconds, while between attacks, at a time when the pulse rate was only 73 , the $a-c$ time averaged 0.17 seconds. Figure 4 is a tracing taken when the heart's action was slow and shows a normal "auricular" venous pulse with $a, c$ and $v$ waves. Both of these cases, therefore, seem to belong to that class in which the normal sequence of auricular and then ventricular contraction is replaced during 
the paroxysms of tachycardia by a condition in which all evidence of contraction of the auricle is lost, and in which the venous pulse only shows a wave due to contraction of the rentricle. 'The cause of this absence of a contraction on the part of the auricle has not, as yet, been satisfactorily determined. There are, however, various conceptions which seek to explain the conditions in paroxysmal tachycardia.

Hoffmann ${ }^{s}$ was struck by the fact that in attacks of paroxysmal tachycardia the normal rate of the heart is approximately, doubled or quadrupled. As an explanation of this fact, he assumed that at a point above the auricles-in the veins-stimulus-formation went on at a more rapid rate than that to which the heart could respond. Owing to diminished irritability, contractability, and conductivity-a sino-auricular

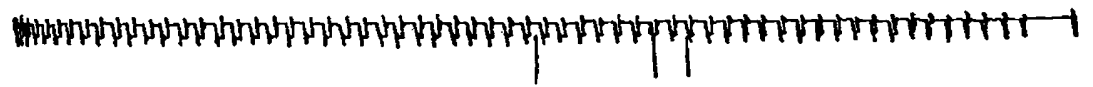

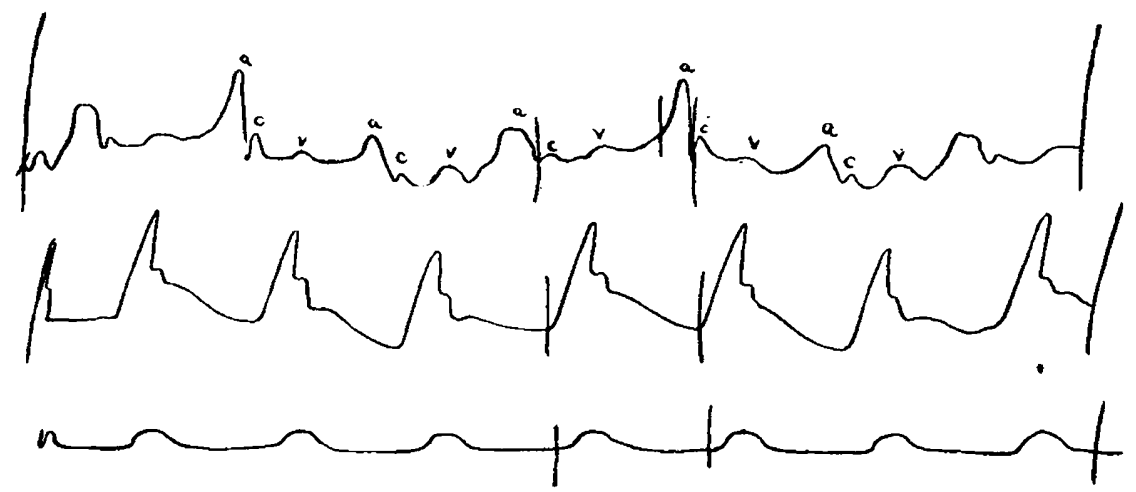

Fig. 4.--Yormal venous pulse, Case 2; pulse rate, 73 .

block-the auricles respond normally to only every second or every fourth stimulus arising in the veins. During the attacks there is a letting up of the normal sino-auricular block, the heart is enabled to follow the rhythm of the veins, and its rate is increased two or fourfold. While such a mechanism is an ingenious explanation of those cases of paroxysmal tachycardia in which there is a simple relation between the rates and during the attacks-although by no means all cases are of this typethere is very little experimental evidence in favor of such a theory.

According to Mackenzie, ${ }^{7}$ in paroxysmal tachycardia the normal sequence of the heart's action is replaced by what he terms the "nodal

8. Hoffman: Verdoppelung der Herzfrequenz. Ztschr. f. klin. Med., 1904, liii, 206. 
rhythm," in which the stimulus to contraction no longer begins at the venous sinus and passes to the auricle and then to the ventricle, but in which the stimulus originates in the "auriculoventricular node" of T'awara and causes a simultaneous contraction of auricles and ventricles -extrasystoles with shortened conduction time. This is the same typc of ventricular rhythm which Mackenzie has described as occurring in the "absolutely irregular heart." While, however, the nodal rhythm usually gives rise to markedly irregular heart action, nodal extrasystoles may be produced in groups in which the rate is very rapid and the rhythm regular. 'The essential characteristic of the venous pulse in "nodal rhythm" is the absence of any wave due to auricular systole and the presence of " "ventricular venous pulse." In two of the cases reported by Mackenzic. postmortem examinations showed that the auriculoventricular bundle was pathologically affected. In one case there was infiltration by plasma cells, while in the other case the artery supplying the bundle was obliterated and there was probably disease of the bundle itself. These two instances "afford support for the view that the auriculorentricular node or bundle, by the invasion of the diseased processes, is rendered more irritable than the sinus remains, and on account of the excessive irritability starts the rhythm of the heart." Mackenzie goes so far as to affirm ti:at the term "paroxysmal tachycardia" should be used only to cover" those cases in which the "nodal rhythm" is present. Those cases of tachycardia in which ventricular contractions follow auricular contractions, as normally, he refers to as "attacks of palpitation." In the latter, he states, the rate rarely rises above 1\%0. Mackenzie gives venous tracings from seren cases which showed "transient nodal rhythm" or typical attacks of paroxysmal tachycardia.

Rihl also has reported a case in which there were sudden changes of heart rate associated with changes in the renous pulse. When the heart was slow the venous pulse was of the normal character, but during the rapid phases only one wave was present-a wave occurring synchronously with the cubital pulse, after the ventricular contraction, and apparenty due to the contraction of the auricle. Rihl concluded that during the periods of tachycardia the stimulus to contraction arose in the auriculorentricular region.

On the basis of experimental evidence Hirschfelder ${ }^{1}$ has suggesteil that the canse of those cases of paroxysmal tachycardia which are characterized by the ventricular type of renous pulse is fibrillation of the auricles. By means of strong faradic stimulation applied to the auricle of a dog's heart he was able to produce auricular fibriliation, together with a sudden increase in the ventricular rate to approximately double 
the normal. Botle conditions outlasted the period of faradization, and in some cases werc stopped by stimulation of the vagus. While it is, of course, impossible to prove that in paroxysmal tachycardia in man the auricles are in a state of fibrillation, such an explanation would account for the absence of evidence of auricular contraction, together with the sudden increase in rentricular rate which is seen in most cases, and the experimental evidence makes the work peculiarly suggestive.

Cushny and Edmunds ${ }^{9}$ have also observed auricular fibrillation in ilogs, and have suggested that the condition may be the cause of jaroxysmal arrhythmia in man. In their cases the fibrillation was seen immediately after opening the chest, and was apparently due to a reftex from the sensory stimuli produced by the operation. The two theories of Mackenzie and of Hirschfelder are, however, not necessarily opposed to one another. 'The essential point in Mackenzices theory is that the waves on the venous pulse in paroxysmal tachycardia represent extra systoles with shortened conduction time arising in the atrio-ventricular nodes. It is of importance, first, that Retzer" has shown clearly that the node of Tawara can not be found in either the embryonic or adult liuman heart. Second, Hirschfelder has demonstrated experimentally "that extrasystoles with shortened conduction time may arise as a result of stimuli applied directly to the auricles, and need not necessarily indicate the presence of an irritative lesion within the bundle of His or even within the system of Purkinje fibers." Thus it is quite possible that the contractions of the heart in paroxysmal tachycardia are extrasystole: with shortened contraction time, the original stimulus to which arises in an auricle which is unduly irritable or which has passed into fibrillation.

The tracings which were obtained from the cases reported here might well be explained on the basis either of Mackenzie's or of Hirschfelder's theories. On the one hand, the "ventricular" venous pulse might be dut to the rapid formation of stimuli in the auriculorentricular bundle, causing both chambers of the heart to contract simultaneously, with the result that only one wave is seen on the renous pulse. On the other hand, there might be fibrillation of the auricles, so that no auricular wave is registered, in which case the ware on the renous pulse is due to rentricular contraction alone.

I am greatly indebted to Dr. W. S. Thayer and Dr. A. D. Hirschfelder for their kind assistance.

9. Cushny and Edmunds: Patroxysmal irreguhary of the heart and auricular fibrillation. Am. Jour. Med. Sc. 1907 , exxxiii. 66 .

10. Retzer: Some results of recent investigations on the mammalian heart. Anat. Rec., 1908, ii. 149 . 